\title{
Construction of Intensity-Duration-Frequency Curves for Precipitation with Annual Maxima Data in Kumulur Region
}

\author{
Vanitha, S. ${ }^{*}$ and V. Ravikumar
}

Dept. of Soil and Water Conservation Engineering and Agricultural Structures, Agricultural Engineering College and Research Institute, Tamil Nadu Agricultural University, Kumulur, Trichy (621 712), India

\section{Corresponding Author}

Vanitha, $\mathrm{S}$.

e-mail: vanitha.subramani636@gmail.com

\author{
Article History \\ Article ID: AR1823 \\ Received in $27^{\text {th }}$ June, 2017 \\ Received in revised form $16^{\text {th }}$ September, 2017 \\ Accepted in final form $4^{\text {th }}$ October, 2017
}

\begin{abstract}
Intensity-duration-frequency (IDF) relationship of rainfall amounts is one of the most commonly used tools in water resources engineering for planning, design and operation of water resources projects. The Intensity-Duration-Frequency relationship is a mathematical relationship between the rainfall intensity, duration and return period. This relationship is determined through statistical analysis of recorded rainfall data. The objective of this study is to derive IDF relationship of rainfall at Kumulur region. A total durations ranging from 10 minutes to $24 \mathrm{hr}$ (10 min, $20 \mathrm{~min}, 30 \mathrm{~min}, 60 \mathrm{~min}, 120 \mathrm{~min}, 180 \mathrm{~min}, 360 \mathrm{~min}, 720 \mathrm{~min}$ and $1440 \mathrm{~min}$ ) for return periods of 2, 5, 10, 25, 50 and 100 years were analyzed. In this study, Yearly maximum rainfall data for Kumulur (1991-2014) was used. Empirical reduction formula of Indian Meteorological Department (IMD) has been used to estimate the short duration rainfall intensity from yearly maximum rainfall data. Gumbel and Log Pearson Type III (LPT III) Distribution method was used to construct IDF curves and equations. The results obtained using Gumbel method is somewhat higher than the outcomes obtained using the LPT III distribution method. The chi-square goodness of fit test was used to determine the best fit probability distribution. This study will be helpful in many design problems related to watershed management, such as runoff disposal and erosion control, it is necessary to know the rainfall intensities of different durations and different return periods.
\end{abstract}

Keywords: Rainfall, intensity, duration, frequency, gumbel, LPT III

\section{Introduction}

Rainfall intensity-duration-frequency curves are graphical representations of the amount of water that falls within a given period of time in catchment areas (Dupont and Allen, 2000).

Degradation of water quality, property damage and potential loss of life due to flooding is caused by extreme rainfall events. Historic rainfall event statistics (in terms of intensity, duration, and return period) are used to design flood protection structures and many other civil engineering structures involving hydrologic flows (McCuen, 1998; Prodanovic et al., 2007). Any change in climate produces modifications in extreme weather events, such as heavy rainfall, heat and cold waves, in addition to prolonged drought occurrences (Almazroui et al., 2012). Since rainfall characteristics are often used to design water structures, reviewing and updating rainfall characteristics (i.e., Intensity-Duration-Frequency (IDF) curves) for future climate scenarios is necessary (Mirhosseini et al., 2013).

Mathematical relation between the parameters-Return period $\mathrm{T}$ (which is also known as frequency referring to the annual frequency of exceedance f), Rainfall intensity I and Duration d can easily be found from the IDF curves (Elsebaie, 2012; Koutsoyiannis et al., 1998; Koutsoyiannis, 2003). The rainfall intensity can be found for a particular return period for varying durations of storm using the IDF curve or conversely, the IDF curve can be used for finding out the return period of a rainfall. (Matin et al., 1984) Developed the IDF curve for North-East region Bangladesh and also observed that the rainfall data in this region follow Extreme Value Type I or Gumbel distribution. (Chowdhury et al., 2007), develop the short duration rainfall IDF curve for Sylhet with return period of 2, 5, 10, 20, 50 and 100 years. But still there is the scope to identify a perfect from of IDF empirical formula for Sylhet out of widely used forms.

Three probability distribution analysis methods namely Log Pearson Type III, Gumbel and Log normal were used (AlHassoun, 2011) for developing a basic formula for approximating rainfall intensity in Riyadh (Saudi Arabia) and this formula could be used instead of developing an IDF curve. The main objectives of this study was to find the best probability distribution function for the annual maximum rainfall data by chi-square test as well as to develop short duration rainfall IDF curve with empirical equation for various 
return period in Kumulur Region.

\section{Materials and Methods}

\subsection{Data collection}

For this study $24 \mathrm{hr}$ daily rainfall data for Kumulur (1991-2014) was collected from Agro climate Research Centre (ACRC), Tamilnadu Agricultural University (TNAU). From the daily data, maximum yearly rainfall data was used in the analysis (Table 1).

Table 1: Maximum daily rainfall recorded in Kumulur during 1991-2014

\begin{tabular}{lccccc}
\hline Year & ODMR & Year & ODMR & Year & ODMR \\
\hline 1991 & 151.0 & 1999 & 206.0 & 2007 & 158.0 \\
1992 & 85.1 & 2000 & 90.5 & 2008 & 149.0 \\
1993 & 106.0 & 2001 & 84.0 & 2009 & 176.0 \\
1994 & 71.8 & 2002 & 157.0 & 2010 & 137.0 \\
1995 & 100.0 & 2003 & 57.6 & 2011 & 78.5 \\
1996 & 123.0 & 2004 & 116.0 & 2012 & 94.4 \\
1997 & 69.7 & 2005 & 115.0 & 2013 & 80.0 \\
1998 & 120.0 & 2006 & 69.9 & 2014 & 67.0 \\
\hline
\end{tabular}

ODMR: One day maximum rainfall $(\mathrm{mm})$

\subsection{Constructing of IDF curves}

IDF curves are developed through a three step procedure Chow (1988); Singh (1992). Firstly, the records are fit into any of the probability distribution functions for a specific time period, for instance 10 minutes, 20 minutes, 30 minutes, 1 hour, ... 24 hour. After it is completed, the probability distribution function selected for determining rainfall intensities for a specific time period and return period like 2 , $5,10,50,100$ years, etc. Lastly, two approaches can be used: (a) an equation or mathematical relation is developed relating rainfall intensities, return periods and time durations, (b) a graphical illustration of the rainfall intensities determined for specific time durations and return periods.

\subsection{Estimation of short duration rainfall}

Indian Meteorological Department (IMD) use an empirical reduction formula (Eq. 1) for estimation of various duration like 1-hr, 2-hr, 3-hr, 5-hr, 6-hr and 12-hr rainfall values from annual maximum values. IMD empirical reduction formula was used to estimate the short duration rainfall from daily rainfall data in Sylhet city and found that this formula give the best estimation of short duration rainfall (Chowdhury et al., 2007). In this study this empirical formula (Eq. 1) was used to estimate short duration rainfall in Kumulur region.

$\mathrm{P}_{\mathrm{t}}=\mathrm{P}_{24} \quad \rightarrow(1)$

Where,

$P_{t}$ is the required rainfall depth in $\mathrm{mm}$ at $\mathrm{t}$-hr duration

$\mathrm{P}_{24}$ is the daily rainfall in $\mathrm{mm}$ $t$ is the duration of rainfall for which the rainfall depth is required in $\mathrm{hr}$

\subsection{Gumbel theory of distribution}

Gumbel distribution methodology was selected to perform the flood probability analysis. The Gumbel theory of distribution is the most widely used distribution for IDF analysis owing to its suitability for modelling maxima. It is relatively simple and uses only extreme events (maximum values or peak rainfalls). The Gumbel method calculates the 2, 5, 10, 25, 50 and 100 year return intervals for each duration period and requires several calculations. Frequency precipitation $\mathrm{P}_{\mathrm{T}}$ (in $\mathrm{mm}$ ) for ach duration with a specified return period $\mathrm{T}$ (in year) is given by the following equation:

$\mathrm{P}_{\mathrm{T}}=\mathrm{P}_{\text {ave }}+\mathrm{KS} \quad \rightarrow(2)$

Where, $\mathrm{K}$ is Gumbel frequency factor given by:

$\mathrm{K}=-[0.5772+\ln [\ln [\mathrm{T} /(\mathrm{T}-1)]]] \rightarrow(3)$

Where

$P_{\text {ave }}$ is the average of the maximum precipitation corresponding to a specific duration.

In utilizing Gumbel distribution, the arithmetic average in Eq. (2) is used:

$P_{\text {ave }}=1 / n \rightarrow(4)$

Where

$P_{i}$ is the individual extreme value of rainfall

$\mathrm{n}$ is the number of events or years of record

The standard deviation is calculated by Eq. (5) computed using the following relation:

$S=[1 /(n-1) \rightarrow(5)$

Where, $\mathrm{S}$ is the standard deviation of $\mathrm{P}$ data. The frequency factor $(K)$, which is a function of the return period and sample size, when multiplied by the standard deviation gives the departure of a desired return period rainfall from the average. Then the rainfall intensity, $\mathrm{I}_{\mathrm{T}}(\mathrm{mm} / \mathrm{h})$ for return period $\mathrm{T}$ is obtained from:

$\mathrm{I}_{\mathrm{T}}=\mathrm{P}_{\mathrm{t}} / \mathrm{T}_{\mathrm{d}} \rightarrow(6)$

Where, $T_{d}$ is duration in hours.

The frequency of rainfall is usually defined with reference to the annual maximum series, which consists of the largest values observed in each year. An alternative data format for rainfall frequency studies is based on the peak-over threshold concept, which consists of all precipitation amounts above certain thresholds selected for different durations. Due to its simpler structure, the annual-maximum-series method is more popular in practice (Borgaet et al., 2005).

From the raw data, the maximum precipitation $(P)$ and the statistical variables (average and standard deviation) for each duration $(10,20,30,60,120,180,360,720$ and $1440 \mathrm{~min})$ were computed. Table 2 shows the computed frequency precipitation $\left(P_{T}\right)$ values and intensities $\left(I_{T}\right)$ for different durations and six return periods following the methodology previously described

\subsection{Log pearson type (LPT) III}

The LPT III probability model is used to calculate the rainfall intensity at different rainfall durations and return periods 
Table 2: Computed frequency precipitation values and intensities for different durations and return periods using Gumbel Method for Kumulur

\begin{tabular}{|c|c|c|c|c|c|c|c|c|c|c|c|}
\hline \multirow[t]{2}{*}{ Pavg } & & \multicolumn{3}{|c|}{$10 \mathrm{~min}$} & \multicolumn{2}{|c|}{$20 \mathrm{~min}$} & \multicolumn{3}{|c|}{$30 \mathrm{~min}$} & \multicolumn{2}{|c|}{$60 \mathrm{~min}$} \\
\hline & & \multicolumn{3}{|c|}{21.214} & \multicolumn{2}{|c|}{26.695} & \multicolumn{3}{|c|}{30.56} & \multicolumn{2}{|c|}{38.5} \\
\hline \multicolumn{3}{|l|}{$S$} & \multicolumn{2}{|c|}{7.516} & \multicolumn{2}{|c|}{9.459} & \multicolumn{3}{|c|}{10.830} & \multicolumn{2}{|c|}{13.641} \\
\hline $\begin{array}{l}\mathrm{T} \\
\text { (year) }\end{array}$ & \multicolumn{2}{|l|}{ K } & $\begin{array}{l}\mathrm{P}_{\mathrm{T}} \\
\mathrm{mm}\end{array}$ & $\begin{array}{c}\mathrm{I}_{\mathrm{T}} \\
\mathrm{mm} \mathrm{hr}^{-1}\end{array}$ & $\begin{array}{c}\mathrm{P}_{\mathrm{T}} \\
\mathrm{mm}\end{array}$ & 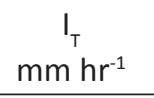 & $\begin{array}{l}\mathrm{P}_{\mathrm{T}} \\
\mathrm{mm}\end{array}$ & \multicolumn{2}{|c|}{$\begin{array}{c}\mathrm{I}_{\mathrm{T}} \\
\mathrm{mm} \mathrm{hr}^{-1}\end{array}$} & $\begin{array}{l}\mathrm{P}_{\mathrm{T}} \\
\mathrm{mm}\end{array}$ & $\begin{array}{c}\mathrm{I}_{\mathrm{T}} \\
\mathrm{mm} h r^{-1}\end{array}$ \\
\hline 2 & \multicolumn{2}{|c|}{-0.164} & 19.979 & 119.872 & 25.140 & 75.421 & 28.785 & \multicolumn{2}{|c|}{57.570} & 36.258 & 36.258 \\
\hline 5 & \multicolumn{2}{|c|}{0.719} & 26.624 & 159.745 & 33.503 & 100.509 & 38.360 & \multicolumn{2}{|c|}{76.720} & 48.319 & 48.319 \\
\hline 10 & \multicolumn{2}{|c|}{1.305} & 31.024 & 186.145 & 39.040 & 117.120 & 44.699 & \multicolumn{2}{|c|}{89.398} & 56.304 & 56.304 \\
\hline 25 & \multicolumn{2}{|c|}{2.044} & 36.583 & 219.501 & 46.036 & 138.107 & 52.709 & 105.4 & & 66.393 & 66.393 \\
\hline 50 & 2.59 & & .708 & 244.246 & 51.225 & 153.676 & 58.651 & 117.3 & & 73.878 & 73.878 \\
\hline 100 & 3.13 & & .801 & 268.809 & 56.377 & 169.130 & 64.549 & 129.0 & & 81.307 & 81.307 \\
\hline Table & ontin & ue... & & & & & & & & & \\
\hline & avg & & $\min$ & 180 & $\min$ & 360 & $\min$ & 720 & $\min$ & & 440 \\
\hline & & & 496 & & 507 & 69. & & 88. & 771 & 110. & .937 \\
\hline & $S$ & & 183 & & 667 & & & 31. & 206 & & 308 \\
\hline $\begin{array}{c}\mathrm{T} \\
\text { (year) }\end{array}$ & K & $\begin{array}{c}\mathrm{P}_{\mathrm{T}} \\
\mathrm{mm}\end{array}$ & $\begin{array}{c}\mathrm{I}_{\mathrm{T}} \\
\mathrm{mm} \mathrm{hr}^{-1}\end{array}$ & $\begin{array}{c}\mathrm{P}_{\mathrm{T}} \\
\mathrm{mm}\end{array}$ & $\begin{array}{c}\mathrm{I}_{\mathrm{T}} \\
\mathrm{mm} \mathrm{hr}^{-1}\end{array}$ & $\begin{array}{c}\mathrm{P}_{\mathrm{T}} \\
\mathrm{mm}\end{array}$ & $\begin{array}{c}\mathrm{I}_{\mathrm{T}} \\
\mathrm{mm} \mathrm{hr}^{-1}\end{array}$ & $\begin{array}{c}\mathrm{P}_{\mathrm{T}} \\
\mathrm{mm}\end{array}$ & $\begin{array}{c}\mathrm{I}_{\mathrm{T}} \\
\mathrm{mm} \mathrm{hr}^{-1}\end{array}$ & $\begin{array}{c}\mathrm{P}_{\mathrm{T}} \\
\mathrm{mm}\end{array}$ & $\begin{array}{c}\mathrm{I}_{\mathrm{T}} \\
\mathrm{mm} \mathrm{hr}^{-1}\end{array}$ \\
\hline 2 & -0.164 & 45.672 & 22.836 & 52.275 & 17.425 & 65.847 & 10.974 & 82.943 & 6.912 & 104.477 & 4.353 \\
\hline 5 & 0.719 & 60.864 & 30.432 & 69.663 & 23.221 & 87.749 & 14.625 & 110.531 & 9.211 & 139.229 & 5.801 \\
\hline 10 & 1.305 & 70.922 & 35.461 & 81.175 & 27.058 & 102.250 & 17.042 & 128.798 & 10.733 & 162.238 & 6.760 \\
\hline 25 & 2.044 & 83.631 & 41.815 & 95.721 & 31.907 & 120.573 & 20.095 & 151.877 & 12.656 & 191.309 & 7.971 \\
\hline 50 & 2.592 & 93.059 & 46.529 & 106.512 & 35.504 & 134.165 & 22.361 & 168.999 & 14.083 & 212.876 & 8.870 \\
\hline 100 & 3.137 & 102.417 & 51.209 & 117.223 & 39.074 & 147.657 & 24.610 & 185.994 & 15.499 & 234.284 & 9.762 \\
\hline
\end{tabular}

to form the historical IDF curves for each station. LPT III distribution involves logarithms of the measured values. The mean and the standard deviation are determined using the logarithmically transformed data. In the same manner as with Gumbel method, the frequency precipitation is obtained using LPT III method. The simplified expression for this distribution is given as follows:

$P^{*}=\log \left(P_{i}\right) \rightarrow(7)$

$\mathrm{P}_{\mathrm{T}}^{*}=\mathrm{P}_{\text {ave }}{ }^{*}+\mathrm{K}_{\mathrm{T}} \mathrm{S}^{*} \rightarrow(8)$

$\mathrm{P}_{\text {ave }}{ }^{*}=1 / \mathrm{n} \sum_{i=1}^{n} \mathrm{P}^{*} \quad \rightarrow(9)$

$S^{*}=\left[1 /(n-1) \sum_{i=1}^{n}\left(P^{*}-P_{\text {avg }}{ }^{*}\right) 2\right] 1 / 2 \quad \rightarrow(10)$

Where $\mathrm{P}_{\mathrm{T}}{ }^{*}$, Pave*, $\mathrm{S}^{*}$ are as defined previously but based on the logarithmically transformed $\mathrm{P}_{\mathrm{i}}$ values; i.e. $\mathrm{P}^{*}$ of Eq. (7). $K_{T}$ is the Pearson frequency factor which depends on return period (T) and skewness coefficient (CS). The skewness coefficient, Cs, is required to compute the frequency factor for this distribution. The skewness coefficient is computed by Eq. (11) (see Chow, 1988 ; Burke and Burke, 2008).

$\mathrm{Cs}=\frac{n \sum_{i=1}^{n}\left(\mathrm{P}_{i}^{*} \mathrm{P}_{\text {avg }}{ }^{*}\right) 3}{(\mathrm{~N}-1)(\mathrm{N}-2)\left(\mathrm{S}^{*}\right) 3} \rightarrow(11)$
$\mathrm{K}_{\mathrm{T}}$ values can be obtained from tables in many hydrology references; for example reference (Chow, 1988). By knowing the skewness coefficient and the recurrence interval, the frequency factor, KT for the LPT III distribution can be extracted. The antilog of the solution in Eq. (7) will provide the estimated extreme value for the given return period. Table 3 show the computed frequency precipitation $P_{T}$ values and intensities $\mathrm{I}_{\mathrm{T}}$ for six different durations and six return periods using LPT III methodology.

\subsection{Goodness of fit test}

The aim of the test is to decide how good is a fit between the observed frequency of occurrence in a sample and the expected frequencies obtained from the hypothesized distributions. A goodness-of-fit test between observed and expected frequencies is based on the chi-square quantity, which is expressed as,

$\lambda_{2}=\sum_{i}^{k}=1 \frac{(O i-E i) 2}{E i}(O i-E i) 2 \rightarrow(13)$

Where

$\lambda^{2}$ is a random variable whose sampling distribution is approximated very closely by the chi-square distribution. The symbols Oi and Ei represent the observed and expected 
Table 3: Computed frequency precipitation values and intensities for different durations and return periods using LPT III Method for Kumulur

\begin{tabular}{|c|c|c|c|c|c|c|c|c|c|c|}
\hline \multirow{2}{*}{$\begin{array}{l}\mathrm{T} \\
\text { (year) }\end{array}$} & \multirow[t]{2}{*}{ K } & \multicolumn{3}{|c|}{$10 \mathrm{~min}$} & \multicolumn{3}{|c|}{$20 \mathrm{~min}$} & \multicolumn{3}{|c|}{$30 \mathrm{~min}$} \\
\hline & & $\begin{array}{l}\mathrm{P} * \mathrm{~T} \\
\mathrm{~mm}\end{array}$ & PT mm & $\begin{array}{c}\text { IT } \\
\mathrm{mm} \mathrm{hr}^{-1}\end{array}$ & $\begin{array}{l}\mathrm{P}^{*} \mathrm{~T} \\
\mathrm{~mm}\end{array}$ & PT mm & $\begin{array}{c}\text { IT } \\
\mathrm{mm} \mathrm{hr} r^{-1}\end{array}$ & $\begin{array}{l}\mathrm{P} * \mathrm{~T} \\
\mathrm{~mm}\end{array}$ & PT mm & 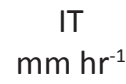 \\
\hline 2 & -0.017 & 1.299 & 19.907 & 119.442 & 1.399 & 25.061 & 75.183 & 1.457 & 28.642 & 57.284 \\
\hline 5 & 0.836 & 1.427 & 26.73 & 160.38 & 1.527 & 33.651 & 100.953 & 1.586 & 38.548 & 77.096 \\
\hline 10 & 1.292 & 1.496 & 31.333 & 187.998 & 1.596 & 39.446 & 118.338 & 1.655 & 45.186 & 90.372 \\
\hline 25 & 1.785 & 1.570 & 37.154 & 222.924 & 1.670 & 46.774 & 140.322 & 1.729 & 53.58 & 107.16 \\
\hline 50 & 2.107 & 1.619 & 41.591 & 249.546 & 1.718 & 52.24 & 156.72 & 1.777 & 59.841 & 119.682 \\
\hline 100 & 2.4 & 1.663 & 46.026 & 276.156 & 1.763 & 57.943 & 173.829 & 1.821 & 66.222 & 132.444 \\
\hline \multicolumn{11}{|c|}{ Table 3: Continue... } \\
\hline \multirow{2}{*}{$\begin{array}{l}\mathrm{T} \\
\text { (year) }\end{array}$} & \multirow[t]{2}{*}{ K } & \multicolumn{3}{|c|}{$60 \mathrm{~min}$} & \multicolumn{3}{|c|}{$120 \mathrm{~min}$} & \multicolumn{3}{|c|}{$180 \mathrm{~min}$} \\
\hline & & $\begin{array}{l}\mathrm{P} * \mathrm{~T} \\
\mathrm{~mm}\end{array}$ & PT mm & 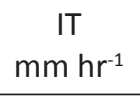 & $\begin{array}{l}\mathrm{P}^{*} \mathrm{~T} \\
\mathrm{~mm}\end{array}$ & PT mm & $\begin{array}{c}\text { IT } \\
\mathrm{mm} \mathrm{hr}^{-1}\end{array}$ & $\begin{array}{l}\mathrm{P} * \mathrm{~T} \\
\mathrm{~mm}\end{array}$ & PT mm & $\begin{array}{c}\text { IT } \\
\mathrm{mm} \mathrm{hr}^{-1}\end{array}$ \\
\hline 2 & -0.017 & 1.558 & 36.141 & 36.141 & 1.658 & 45.499 & 22.749 & 1.717 & 52.119 & 17.373 \\
\hline 5 & 0.836 & 1.686 & 48.529 & 48.529 & 1.786 & 61.094 & 30.547 & 1.845 & 69.984 & 23.328 \\
\hline 10 & 1.292 & 1.755 & 56.885 & 56.885 & 1.855 & 71.614 & 35.807 & 1.914 & 82.035 & 27.345 \\
\hline 25 & 1.785 & 1.829 & 67.453 & 67.453 & 1.929 & 84.918 & 42.459 & 1.988 & 97.275 & 32.425 \\
\hline 50 & 2.107 & 1.877 & 75.336 & 75.336 & 1.978 & 95.06 & 47.53 & 2.036 & 108.643 & 36.214 \\
\hline 100 & 2.4 & 1.922 & 83.368 & 83.368 & 2.022 & 105.196 & 52.598 & 2.080 & 120.226 & 40.075 \\
\hline \multicolumn{11}{|c|}{ Table 3: Continue... } \\
\hline \multirow{2}{*}{$\begin{array}{l}\mathrm{T} \\
\text { (year) }\end{array}$} & \multirow[t]{2}{*}{ K } & \multicolumn{3}{|c|}{$360 \mathrm{~min}$} & \multicolumn{3}{|c|}{$720 \mathrm{~min}$} & \multicolumn{3}{|c|}{$1440 \mathrm{~min}$} \\
\hline & & $\begin{array}{l}\mathrm{P}^{*} \mathrm{~T} \\
\mathrm{~mm}\end{array}$ & PT mm & $\begin{array}{c}\text { IT } \\
\mathrm{mm} \mathrm{hr}^{-1}\end{array}$ & $\begin{array}{l}\mathrm{P}^{*} \mathrm{~T} \\
\mathrm{~mm}\end{array}$ & PT mm & $\begin{array}{c}\text { IT } \\
\mathrm{mm} \mathrm{hr}{ }^{-1}\end{array}$ & $\begin{array}{l}\mathrm{P}^{*} \mathrm{~T} \\
\mathrm{~mm}\end{array}$ & PT mm & 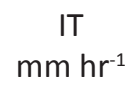 \\
\hline 2 & -0.017 & 1.817 & 65.615 & 10.935 & 1.917 & 82.604 & 6.883 & 2.017 & 103.992 & 4.333 \\
\hline 5 & 0.836 & 1.945 & 88.105 & 14.684 & 2.045 & 110.917 & 9.243 & 2.146 & 139.959 & 5.831 \\
\hline 10 & 1.292 & 2.014 & 103.276 & 17.212 & 2.114 & 130.017 & 10.834 & 2.214 & 163.682 & 6.820 \\
\hline 25 & 1.785 & 2.088 & 122.462 & 20.410 & 2.188 & 154.17 & 12.847 & 2.289 & 194.536 & 8.105 \\
\hline 50 & 2.107 & 2.137 & 137.088 & 22.848 & 2.237 & 172.584 & 14.382 & 2.337 & 217.27 & 9.052 \\
\hline 100 & 2.4 & 2.181 & 151.705 & 25.284 & 2.281 & 190.985 & 15.915 & 2.381 & 240.436 & 10.018 \\
\hline
\end{tabular}

frequencies, respectively, for the $\mathrm{i}$-th class interval in the histogram. The symbol $\mathrm{k}$ represents the number of class intervals. If the observed frequencies are close to the corresponding expected frequencies, the $\lambda^{2}$ value will be small, indicating a good fit; otherwise, it is a poor fit. A good fit leads to the acceptance of null hypothesis, whereas a poor fit leads to its rejection. The critical region will, therefore, fall in the right tail of the chi-square distribution. For a level of significance equal to $a$, the critical value is found from readily available chi-square tables and $\lambda^{2}>$ constitutes the critical region (Oyebande, 1982).

\section{Results and Discussion}

The purpose of this study was to develop IDF curves and derive an empirical formula to estimate the rainfall intensity at Kumulur. The IDF curves are used as an aid when designing drainage structures for any engineering project. The curves allow the engineer to design safe and economical flood control measures. Rainfall estimates in $\mathrm{mm}$ and their intensities in $\mathrm{mm} \mathrm{hr}{ }^{-1}$ for various return periods and different durations were analysed using the two techniques: (Gumbel and LPT III). The results are listed in Tables 2-3 for the kumulur regions. According to the IDF curves, rainfall estimates are increasing with increase in the return period and the rainfall intensities decrease with rainfall duration in all return periods. Rainfall intensities rise in parallel with the rainfall return periods. The results obtained from the two methods have good consistency.

From the raw data, the maximum rainfall $(\mathrm{P})$ and the statistical 
variables (average and standard deviation) for each duration $(10,20,30,60,120,180,360,720,1440 \mathrm{~min})$ were calculated. Various duration of rainfalls like 10, 20, 30, 60, 120, 180, 360, 720 and 1440 min were estimated from annual maximum 24 hours rainfall data using Indian Meteorological empirical reduction formula. These estimated various duration data were used in Gumbel Extreme Probability Method and Log Pearson Type III to determine rainfall $\left(P_{T}\right)$ values and intensities $\left(\mathrm{I}_{\mathrm{T}}\right)$ for Kumulur. After finding out the rainfall $\left(\mathrm{P}_{\mathrm{T}}\right)$ values and intensities $\left(I_{T}\right)$ in Figure 1 and 2 Rainfall IDF curves are shown using Gumbel and LPT III method for Kumulur.

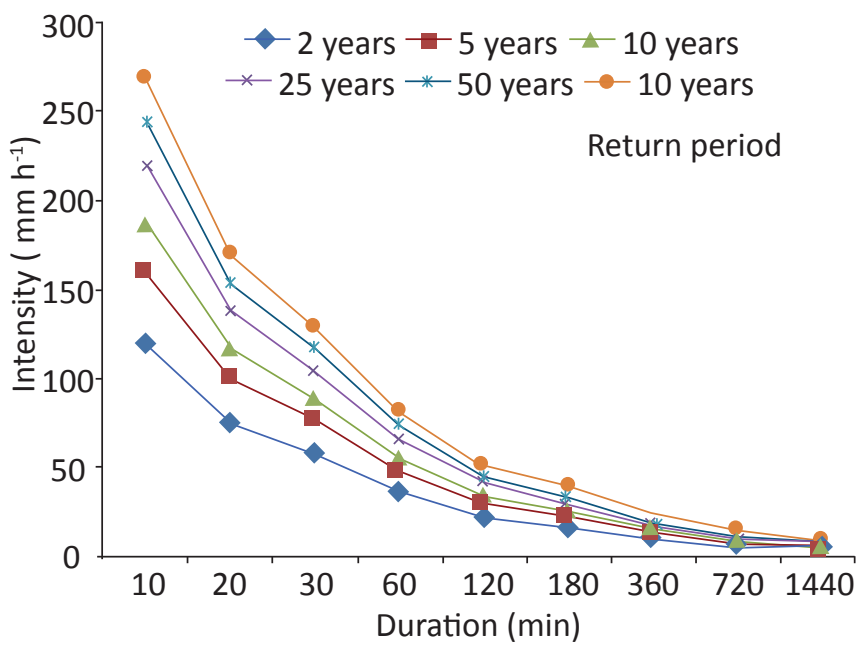

Figure 1: IDF Curves by Gumbel method for Kumulur
It was shown that there were small differences between the results obtained from the two methods, where Gumbel method gives slightly higher results than the results obtained by Log Pearson III.

The goodness-of-fit tests were used to choose the best statistical distribution among those techniques. Results of the chi-square goodness of fit test on annual series of rainfall are shown in Table 4. As it is seen all of the data fit the distributions at the level of significance of $\alpha=0.95$, which yields $\lambda^{2}$ cal $<1.145$. Therefore $\lambda^{2}{ }_{\text {cal }}<\lambda^{2}{ }_{\text {tab }}$, we accept the null hypothesis. There is good correspondence between theory and experiment.

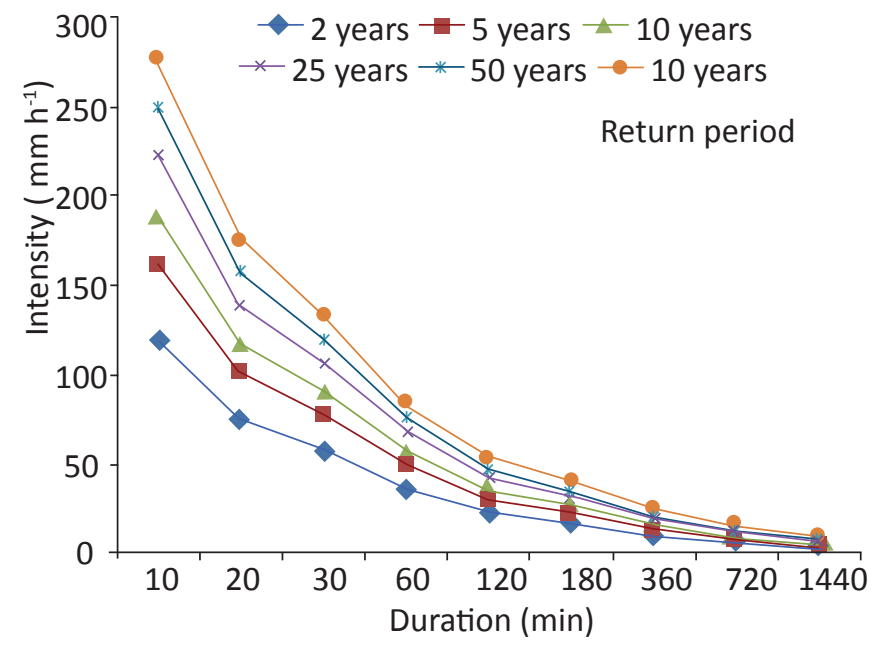

Figure 2: IDF Curves by LPT III method for Kumulur

\begin{tabular}{|c|c|c|c|c|c|c|c|c|c|c|}
\hline \multirow[t]{2}{*}{ Region } & \multirow[t]{2}{*}{ Distribution } & \multicolumn{9}{|c|}{ Duration in minutes } \\
\hline & & 10 & 20 & 30 & 60 & 120 & 180 & 360 & 720 & 1440 \\
\hline \multirow[t]{2}{*}{ Kumulur } & Gumbel & 0.703 & 0.743 & 0.752 & 0.730 & 0.746 & 0.715 & 0.710 & 0.747 & 0.741 \\
\hline & Log pearson type III & 0.752 & 0.726 & 0.737 & 0.748 & 0.730 & 0.728 & 0.740 & 0.730 & 0.728 \\
\hline
\end{tabular}

\section{Conclusion}

Gumbel method gave some larger rainfall intensity estimates compared to LPT III distribution. The chi-square test was used to examine the combinations or contingency of the observed and theoretical frequencies and also to decide about the type of distribution which the available data set follows. The results of the chi-square test showed that in all the durations, the null hypothesis of extreme rainfall series has Gumbel and LPT III distribution which is acceptable at $95 \%$ level of significance.

\section{References}

AlHassoun, S.A., 2011. Developing an empirical formulae to estimate rainfall intensity in Riyadh region. Journal of King Saud University-Engineering Sciences 23, 81-88.

Almazroui, M., Islam, M.N., Athar, H., Jones, P.D., Rahman, M.A., 2012. Recent climate change in the Arabian Peninsula: annual rainfall and temperature analysis of
Saudi Arabia for 1978-2009. International Journal of Climatology 32, 953-966.

Borga, M., Vezzani, C., Fontana, G.D., 2005. “A Regional Rainfall Depth-duration-frequency equations for an alpine region" department of land and agro forest environments, university of padova, legnaro 35020, Italy, Natural Hazards 36, 221-235.

Burke, C.B., Burke, T.T., 2008. Storm Drainage Manual. Indiana LTAP.

Chow, W.T., 1988. Handbook of applied hydrology. McGrawHill.

Chowdhury, R., Alam, J.B., Das, P., Alam, M.A., 2007. "Short duration rainfall estimation of sylhet: imd and uswb method" Journal of Indian Water Works Association, 285-292.

Dupont, B.S., Allen, D.L., 2000. Revision of the rainfall intensity duration curves for the commonwealth of 
Kentucky. Kentucky Transportation Center, College of Engineering, University of Kentucky, USA.

Elsebaie, I.H., 2012. Developing rainfall intensity-durationfrequency relationship for two regions in Saudi Arabia, Journal of King Saud University-Engineering Sciences 24(2), 131-140.

Koutsoyiannis, D., Kozonis, D., Manetas, A., 1998. A mathematical framework for studying rainfall intensityduration-frequency relationships. Journal of Hydrology 206, 118-135.

Koutsoyiannis, D., 2003. "On the appropriateness of the Gumbel distribution in modelling extreme rainfall," in Proceedings of the ESF LESC Exploratory Workshop, Hydrological Risk: recent advances in peak river flow modelling, prediction and real-time forecasting, Assessment of the impacts of land-use and climate changes, European Science Foundation, National Resea. 303-319.
Matin, M.A., Ahmed, S.M.U., 1984. "Rainfall Intensity Duration Frequency Relationship for the N-E Region of Bangladesh" Journal of Water Resource Research.

McCuen, R., 1998. Hydrologic analysis and design. PrenticeHall, Englewood Cliffs, N.J., Mirhosseini, G., Srivastava, P., Stefanova, L., 2013. The impact of climate change on rainfall Intensity-duration-frequency (IDF) curves in Alabama. Reg Environ Change 13(1), 25-33.

Oyebande, L., 1982. Deriving rainfall intensity-durationfrequency relationships and estimates for regions with inadequate data. Hydrological Science Journal 27(3), 353-367.

Prodanovic, P., Simonovic, S.P., 2007. Development of rainfall intensity duration frequency curves for the city of london under the changing climate. Water Resour Res Report, London.

Singh, V.P., 1992. Elementary hydrology. New Jersey: Prentice Hall. 